\title{
obituaries
}

\section{Eva Frommer}

\section{Formerly Consultant Child Psychiatrist, StThomas' Hospital, London}

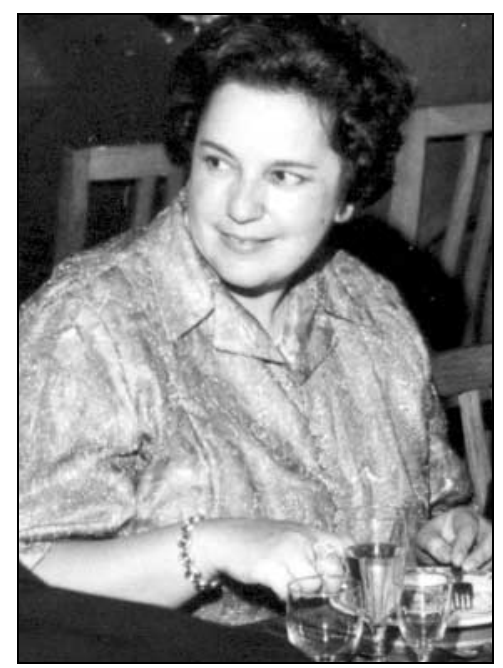

Dr Frommer was a well-known figure both in the child psychiatry world of south London and internationally in the 1960s to 1980s. But because of her severe incapacitating illness in later life, her many services diminished and she, professionally, somewhat faded out of sight.

Eva was born on 6 September 1927 in Berlin to a scientist father and a violinist mother, and always reflected both the scientific and the artistic worlds in her own life. Being of Jewish descent, the family had to leave Germany and come to London, where Eva attended Waldorf (Steiner) schools and was a clever and musical pupil. She decided to study medicine and graduated from the Royal Free Hospital in 1952. She specialised in paediatrics at first, gaining the DCH in 1954. She later trained in psychiatry at the Maudsley, acquiring the DPM in 1962 when she also became a Member of the old RMPA. She became a Foundation Member of the Royal College of Psychiatrists in 1972, and a Fellow in 1981.

After the Maudsley, Eva worked in Sutton, then at St Thomas' Hospital, where she developed child psychiatry in her own unique style. In addition to the out-patient clinic at St Thomas' Hospital, where she worked in close conjunction with the paediatricians, she established a day hospital for children and families in Black Prince Road to which she introduced Waldorf education, anthroposophy, eurhythmy and art therapy. This was a lovely place to visit, an oasis in deprived and dreary Lambeth, because of its emphasis on colour and nature. Either paradoxically or holistically, according to one's point of view, she was also keen to use the newly developed antidepressant drugs for children, recognising childhood depression long before it became fashionable to do so. She published papers, among others, on the day hospital and use of antidepressants for children, and a textbook Diagnosis and Treatment in Clinical Child Psychiatry (Heinemann, 1972), which remains accessible and interesting. Another book, Voyage through Childhood into the Adult World (Pergamon, 1969) was originally written for medical students; in this Eva Frommer both expressed ideas from her own experience and from Steiner's theories of child development; she tried to lead the reader to understand things from a child's point of view, acknowledging and clarifying differences of temperament.

Eva Frommer also translated some of Rudolf Steiner's works, and one of these texts is still in use today. She had wide interests in art, travel, theatre and music, with her expertise sought in those fields. Sadly, her later illness severely curtailed physical expeditions. Eva retired from professional work in 1989 and died on 8 August 2004.

Fiona Subotsky

\section{Kolappa Sundararajan}

\section{Formerly Senior Consultant} Psychiatrist, Halifax

Dr Sundararajan was born in 1928 in South India and died on 8 December 2004. Dr Sundararajan trained in medicine at Madras University. After graduation, in 1954, he worked for about 12 years in India in various branches of medicine, including the prison medical service and private practice as a principal, before coming to the UK in November 1965 to further his experience and knowledge. He worked for 1 year (1966) at the Department of Geriatrics, Burnley District General Hospital, before taking up psychiatry as his chosen branch of medicine in January 1967. After working as a registrar

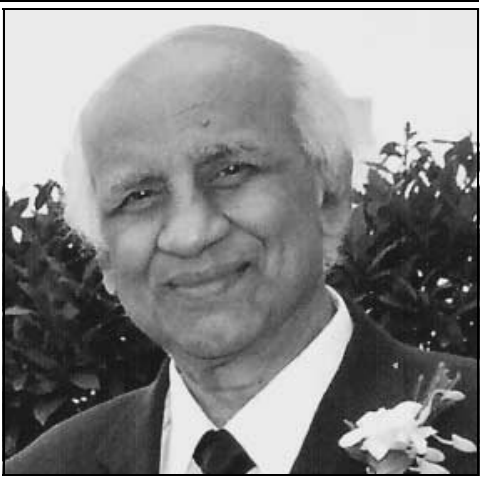

columns (psychiatry), from January 1967 to February 1970, at Bolton District General Hospital, Lancashire, and Netherne Hospital, Coulsdon, Surrey, he was appointed Senior Registrar, Department of Psychiatry at Oldham District General Hospital, Lancashire, a post which he held until February 1974. He obtained the DPM in 1969 and was elected FRCPsych in 2001. He was appointed consultant by Calderdale Health Authority in 1974 and was their first overseas consultant. During his time in Calderdale, he was Chairman of the Division of Psychiatry and was a member of the Specialists Advisory Committee for Yorkshire. He lectured, was engaged in numerous medical research projects, two of which were carried out for Astra and Beecham, and published numerous papers.

After retiring in 1995, he moved to Surrey. However, he found it very difficult withdrawing from professional life and continued to be very active in locum work until 2003. During his retirement, he greatly enjoyed reading and taking long walks, and was able to concentrate more on supporting his charities; this included a 10-km walk in London, in June 2004 for Crusaid, for which he raised $£ 1200$.

Dr Sundararajan was an intelligent, charitable, caring and warm man who was devoted to his profession. He had a wonderful sense of humour, a philosophical and spiritual outlook on life and could reach out to people of all ages and backgrounds. He gave the National Health Service over 38 years of dedicated service. He was extremely well respected by all who worked with him, knew him and were cared for by him; he will never be forgotten.

He leaves a wife Ranjini, three daughters and two grandchildren.

P. Sundararajan 